\title{
Population pharmacogenetics of Ibero-Latinoamerican populations (MESTIFAR 2014)
}

MESTIFAR 2014

28-30 November 2014, Panama City, Panama

The CEIBA consortium was created within the Ibero-American network of Pharmacogenetics (RIBEF) to study population pharmacogenetics. The current status of these initiatives and results of the MESTIFAR project were analyzed in Panama, 28-30 November 2014. The MESTIFAR project focused on studying CYPs genetic polymorphisms in populations of different ethnic origin. So far, more than 6000 healthy volunteers have been evaluated, making this one of the largest population pharmacogenomic studies worldwide. Three symposia were organized, 'Pharmacogenetics of indigenous and mestizos populations and its clinical implications,' 'Methodological innovation in pharmacogenetics and its application in health,' and 'General discussion and concluding remarks,' about mechanisms and proposals for training, diffusion of pharmacogenetics for Spanish- and Portuguese-speaking health professionals, and 'bench to bedside' pilot projects.

Keywords: cytochrome P450 • drug metabolism • genome-wide analyses • Ibero-Americans populations $\bullet$ metabolic phenotypes $\bullet$ next-generation sequencing $\bullet$ pharmacogenetics - population genetics

The Ibero-American network of Pharmacogenetics (RIBEF [1]) is an interdisciplinary group of investigators and health professionals. Its goal is to promote collaborative research in pharmacogenetics and pharmacogenomics in Spanish- and Portuguesespeaking Western-Hemisphere countries. To achieve this goal, members from 16 countries have been involved, including more than 200 investigators who conceive and develop projects focused on the development of pharmacogenetics and personalized medicine in Ibero-America.

In the context of the RIBEF, 13 research groups established the CEIBA Consortium (Consorcio Europeo e Iberoamericano de Farmacogenética de Poblaciones) to study the population pharmacogenetics of Ibero-Americans. The CEIBA Consortium developed the MESTIFAR project (the acronym for the
Spanish term Farmacogenética de Mestizos) that is aimed at determining the haplotype structure and allele frequencies of genes of pharmacogenetics relevance in populations of different ethnic origin (Native Americans [Amerindian] and Mestizos [the result of post-Columbian admixture]) and the promotion of training of Latin American professionals in pharmacogenetics. The MESTIFAR project's goals are: to determine the genotype frequencies of the main genes involved in drug metabolism (CYP2D6, CYP2C9 and CYP2C19), to study the relationship between ancestry (estimated using ancestry-informative markers), pharmacogenetic genotypes and pharmacological phenotypes, and to study the relationship between genotype and metabolic phenotype as shown in previous RIBEF studies in Ecuador, Nicaragua, Cuba, etc. [2-5].
Martha Sosa-Macias ${ }^{\ddagger 1,2}$, Graciela E Moya $a^{\neq 1,3}$, Adrián LLerena ${ }^{*, 1,4}$, Ronald Ramírez ${ }^{1,5}$, Enrique Terán ${ }^{1,6}$, Eva M Peñas-LLedó1,4, Eduardo Tarazona-Santos ${ }^{1,7}$, Carlos Galaviz-Hernández ${ }^{1,2}$, Carolina Céspedes-Garro ${ }^{1,8}$ \& Hildaura Acosta ${ }^{1,9}$

${ }^{1}$ RIBEF Ibero Latino American Network of Pharmacogenetics \& Pharmacogenomics, Mérida, Spain

2IPN-CIIDIR, Unidad Durango, Durango, Mexico

${ }^{3}$ Universidad Católica Argentina, Buenos Aires, Argentina

${ }^{4} \mathrm{CICAB}$ Clinical Research Centre, Extremadura University Hospital \& Medical School, Badajoz, Spain 5UNAN-León, Universidad Nacional Autónoma de Nicaragua, León, Nicaragua

${ }^{6}$ USFQ, Colegio de Ciencias de la Salud, Universidad San Francisco de Quito, Quito, Ecuador

7UFMG, Universidade Federal de Minas Gerais, Belo Horizonte, Brazil

¿UCR, Universidad de Costa Rica, San José, Costa Rica

IUP, Universidad de Panama, Panama

*Author for correspondence: allerena@unex.es

${ }^{\ddagger}$ Authors contributed equally 
On 28-30 November 2014, the RIBEF-CEIBA members met in Panama City. Participants arrived from Argentina, Brazil, Costa Rica, Ecuador, Mexico, Nicaragua, Panama and Spain. The conference was opened by Adrián LLerena (RIBEF Coordinator), who emphasized the symbolism of meeting in Panama, where one of the most famous and earliest interethnic marriage occurred between Vasco Núñez de Balboa (the discoverer of the Pacific Ocean in 1513, from Extremadura) and the indigenous Princess Anayansi.

The first symposium, 'Pharmacogenetics of indigenous and mestizo populations and its clinical implications' was chaired by Ronald Ramírez Roa (UNANLeon, Nicaragua). The first talk was given by Enrique Teran (USFQ, Ecuador) who presented a historical overview of the Ibero-American Program for Science, Technology and Development (CYTED), and how the late Mexican geneticist Jose María 'Chema' Cantú and a Spanish clinical pharmacologist, Adrián LLerena were the keystone for the Iberoamerican Network on Pharmacogenetics [6].

In the next talk, entitled 'The CEIBA Project of study of pharmacogenetics of admixture of Ibero-Americans populations (MESTIFAR),' Adrián LLerena described an overview of the project and a general view of potential relevance for regulatory aspects from a European perspective. So far, more than 6000 healthy volunteers have been evaluated, which constitutes the largest study of population pharmacogenomics developed to date worldwide.

Eva M Peñas-LLedó (UEX, Spain) presented the talk 'Pharmacogenetics, eating disorders and suicide.' Suicide is one of the leading causes of non-natural death in the world; the largest at-risk group is the population of 15-29 years of age. Each year almost 1,000,000 people commit suicide, and in the last 45 years suicide rates have risen by up to $60 \%$ at the global level. There has been described a relationship between personality and activity of CYP2D6 and psychological functioning in Spanish and Cuban healthy volunteers [7-9]. Also, those patients with more than two active CYP2D6 genes (ultrarapid metabolizers, UM) were more frequent among women with eating disorders, suicide cases and severe suicide attempts $[10,11]$. Recently, it has also been published that a high CYP2D6-CYP2C19 metabolic capacity showed an increased risk for a severe suicide attempt, being greater in those patients without a family history of suicide [12]. Finally, she proposed that UM $(2 \mathrm{D} 6+2 \mathrm{C} 19)$ patients who do discontinue or not respond to antidepressant treatment with these CYPs substrates might have an increased risk of severe suicidal attempts and could therefore complete suicide. These data are in agreement with previous from a collaborative project between Spain and Mexico [13].
The second symposium entitled 'Methodological innovation in pharmacogenetics and its application in health' started with Eduardo Tarazona-Santos (UFMG, Brazil) who presented the subject 'Population Genetics, Pharmacogenetics and admixture in the RIBEF context.' His group is using public databases and genome-wide analyses to identify genes and pathways (groups of genes) with a haplotype structure particularly differentiated in native American populations. Two of these genes of interest in pharmacogenetics are COMT and CYP1A1, and they are apparently genes involved in the metabolism of drugs used for the treatment of acute lymphoid leukemia. He also described and discussed the properties of the panel of 83 ancestry informative markers the RIBEF-CEIBA consortium uses to estimate ancestry, and presented the wide spectrum of individual trihybrid continental admixture shown by the individuals studied in MESTIFAR. Finally, he discussed the potential of exome sequencing and admixture mapping as genome-wide strategies to understand the response to drugs in admixed populations.

The second talk entitled 'Molecular analysis for the prediction of metabolic phenotypes' presented by Carlos Galaviz-Hernández (IPN-CIIDIR, Mexico), reviewed the influence of the epigenetic factors (DNA methylation pattern and miRNAs) on the regulation of pharmacogenetically important genes, in which there is found a lack of any genotype-phenotype association. He also discussed the advantages and challenges of using next-generation sequencing technologies (pyrosequencing, Ion semiconductor sequencing and exome sequencing) in pharmacogenetics research.

The third session 'Methods of evaluation of metabolic phenotypes: cocktail CEIBA' Fernando de Andrés (CICAB-UEX, Spain) discussed in vivo phenotyping strategies as an alternative with which to evaluate the interindividual variability in drug metabolism. Later, the novel CEIBA-cocktail approach as a phenotyping tool to evaluate the relationship between genotype and phenotype of five major P450s - (CYP) 1A2, 2C9, 2C19, 3A4 and 2D6 - by selecting the most appropriate probe drugs: caffeine for CYP1A2, losartan for CYP2C9, omeprazole for CYP2C19 and dextromethorphan for the simultaneous evaluation of CYP2D6 and CYP3A4 was discussed [14].

The third symposium, dedicated to the general discussion, conclusions and proposals of RIBEF, had the participation of three PhD students. Fernanda Rodrigues-Soares (UFMG, Brazil) presented individual genomic ancestry analysis in CEIBA populations and how the frequency of polymorphisms varies in $C Y P 2 D 6$, CYP2C9 and CYP2C19 genes according to the ancestry [Ribef-Ceiba Consortium, Unpublished Data]. María Eugenia 
G Naranjo (UEX, Spain) described some of the studies published on CYP2D6 [15-17] and CYP2C9 [18-20] in Ibero-American populations from MESTIFAR project. Finally, Carolina Céspedes-Garro (UC, Costa Rica) presented the results of the study 'Evaluation of scientific activity in Pharmacogenetics in Ibero-American countries' [Ribef-Ceiba Consortium, Unpublished Data]. Major results were that Costa Rica is the major contributor to scientific activity in Pharmacogenetics in Central America and the Caribbean, and that 34\% of the most relevant pharmacogenetic biomarkers have been studied in central America and Caribbean populations. Moreover, differences in the frequency of some of these and in the frequency of metabolic phenotypes in healthy volunteers have been demonstrated, as also has an interethnic variability within central American and with other Latin American populations [21].

Finally, the conference ended with concluding remarks (Population Pharmacogenetics for Iberoamerican populations) presented by Catalina Altami-

\section{References}

\section{RIBEF.}

$$
\text { www.ribef.com }
$$

2 Llerena A, Dorado P, Ramírez R et al. CYP2D6 genotype and debrisoquine hydroxylation phenotype in Cubans and Nicaraguans. Pharmacogenomics J. 12(2), 176-183 (2012).

3 Llerena A, Dorado P, Ramírez R et al. CYP2D6 -1584C>G promoter polymorphism and debrisoquine ultrarapid hydroxylation in healthy volunteers. Pharmacogenomics 14(16), 1973-1977 (2013).

4 Llerena A, Alvarez M, Dorado P et al. Interethnic differences in the relevance of $C Y P 2 C 9$ genotype and environmental factors for diclofenac metabolism in Hispanics from Cuba and Spain. Pharmacogenomics J. 14(3),229-234 (2013).

5 Dorado P, Heras N, Machín E, Hernández F, Teran E, Llerena A. CYP2D6 genotype and dextromethorphan hydroxylation phenotype in an Ecuadorian population. Eur. J. Clin. Pharmacol. 68(5), 637-644 (2012).

6 Penchaszadeh VB, Rojas-Martinez A, Llerena A. A tribute to josé maría ("chema”) cantú. Genet. Mol. Biol. 37(1 Suppl.), 310-314 (2014).

7 Llerena A, Edman G, Cobaleda J, Benítez J, Schalling $\mathrm{D}$, Bertilsson L. Relationship between personality and debrisoquine hydroxylation capacity. Suggestion of an endogenous neuroactive substrate or product of the cytochrome P4502D6. Acta Psychiatr. Scand. 87(1), 23-28 (1993).

8 González I, Peñas-Lledó EM, Pérez B, Dorado P, Alvarez M, LLerena A. Relation between CYP2D6 phenotype and genotype and personality in healthy volunteers. Pharmacogenomics 9(7), 833-840 (2008).

9 Peñas-LLedó EM, Dorado P, Pacheco R, González I, LLerena A. Relation between CYP2D6 genotype, personality, rano (UNAN-León), Humberto Fariñas (UEX, Spain) and Victor Serrano (UP, Panama).

\section{Acknowledgements}

The contribution to the conference and comments to this manuscript of H Fariñas (Spain), C Altamirano (Nicaragua), F de Andrés (Spain), MEG Naranjo (Spain), F Soares-Rodrigues (Brazil), V Serrano (Panama) and CEIBA-Consortium are gratefully acknowledged.

\section{Financial \& competing interests disclosure}

The MESTIFAR project is supported by the Spanish 'Agencia Extremeña de Cooperación Internacional para el Desarrollo,' Gobierno de Extremadura (13IA001). The authors have no other relevant affiliations or financial involvement with any organization or entity with a financial interest in or financial conflict with the subject matter or materials discussed in the manuscript apart from those disclosed.

No writing assistance was utilized in the production of this manuscript.

neurocognition and overall psychopathology in healthy volunteers. Pharmacogenomics 10(7), 1111-1120 (2009).

10 Peñas-Lledó EM, Dorado P, Agüera Z et al. High risk of lifetime history of suicide attempts among CYP2D6 ultrarapid metabolizers with eating disorders. Mol. Psychiatry 16(7), 691-692 (2011).

11 Peñas-Lledó EM, Blasco-Fontecilla H, Dorado P, VaqueroLorenzo C, Baca-García E, Llerena A. CYP2D6 and the severity of suicide attempts. Pharmacogenomics 13(2), 179-184 (2012).

12 Peñas-Lledó E, Guillaume S, Naranjo MEG et al. A combined high CYP2D6-CYP2C19 metabolic capacity is associated with the severity of suicide attempt as measured by objective circumstances. Pharmacogenomics J. doi:10.1038/tpj.2014.42 (2014) (Epub ahead of print).

13 Peñas-Lledó EM, Trejo HD, Dorado P et al. CYP2D6 ultrarapid metabolism and early dropout from fluoxetine or amitriptyline monotherapy treatment in major depressive patients. Mol. Psychiatry 18(1), 8-9 (2013).

14 De Andrés F, Sosa-Macías M, Llerena A. A rapid and simple LC-MS/MS method for the simultaneous evaluation of CYP1A2, CYP2C9, CYP2C19, CYP2D6 and CYP3A4 hydroxylation capacity. Bioanalysis 6(5), 683-696 (2014).

15 LLerena A, Naranjo MEG, Rodrigues-Soares F, PenasLLedó EM, Fariñas H, Tarazona-Santos E. Interethnic variability of CYP2D 6 alleles and of predicted and measured metabolic phenotypes across world populations. Expert Opin. Drug Metab. Toxicol. 10(11), 1569-1583 (2014).

16 Lazalde-Ramos BP, Martínez-Fierro M de la L, GalavizHernández C et al. CYP2D6 gene polymorphisms and predicted phenotypes in eight indigenous groups from northwestern Mexico. Pharmacogenomics 15(3), 339-348 (2014). 
17 López-López M, Peñas-Lledó E, Dorado P et al. CYP2D6 genetic polymorphisms in Southern Mexican Mayan Lacandones and Mestizos from Chiapas. Pharmacogenomics 15(15), 1859-1865 (2014).

18 Dorado P, Beltrán LJ, Machín E, Peñas-Lledó EM, Terán $\mathrm{E}$, Llerena A. Losartan hydroxylation phenotype in an Ecuadorian population: influence of $C Y P 2 C 9$ genetic polymorphism, habits and gender. Pharmacogenomics 13(15), 1711-1717 (2012).

19 Sosa-Macías M, Lazalde-Ramos BP, Galaviz-Hernández C et al. Influence of admixture components on $C Y P 2 C 9^{*} 2$ allele frequency in eight indigenous populations from
Northwest Mexico. Pharmacogenomics J. 13(6), 567-572 (2013).

20 Dorado P, Gallego A, Peñas-LLedó E, Terán E, LLerena A. Relationship between the CYP2C9 IVS8-109A>T polymorphism and high losartan hydroxylation in healthy Ecuadorian volunteers. Pharmacogenomics 15(11), 1417-1421 (2014).

21 Céspedes-Garro C, Naranjo ME, Ramírez R et al. Pharmacogenetics in Central American healthy volunteers: interethnic variability. Drug Metabol. Personal. Ther. 30 (1), 1-71 (2014). 